\title{
Advancing gender equity in medicine
}

\author{
Andrea C. Tricco PhD, Ivy Bourgeault PhD, Ainsley Moore MSc MD, Eva Grunfeld MD DPhil, Nazia Peer MD LLM, \\ Sharon E. Straus MD
}

Cite as: CMAJ 2021 February 16;193:E244-50. doi: 10.1503/cmaj.200951

CMAJ Podcasts: www.cmaj.ca/lookup/doi/10.1503/cmaj.200951/tab-related-content

$\mathbf{T}$ he medical profession has an equity problem, particularly in leadership. Several Canadian studies have highlighted the extent of gender inequity in leadership in medicine, and the extent to which opportunities in academic medicine are inequitable by gender. Gender (as defined in Box 1), in combination with race, religion, sexual orientation and cultural origin, elicits discrimination, including in medicine. In the medical profession, inequities in compensation and career advancement, and discriminatory treatment by peers and patients, has been associated with the intersection of race and gender. Historically, however, research in this area has rarely considered intersectionality.

Gender equity and racial diversity in medicine can promote creative solutions to complex health problems and improve the delivery of high-quality care. We discuss the problem of gender inequity in medicine in Canada, its root causes, the problems inequity raises for the profession and multipronged approaches to promoting equity at all levels of medical organizations, based on best available evidence, as outlined in Box 2.

\section{What is the scale of gender inequity in medical leadership in Canada?}

Although women have outnumbered men in Canadian medical schools for a quarter of a century, women are not equally represented in leadership positions ${ }^{2}$ and are less likely to reach higher ranks than men, even after controlling for age, experience, productivity and specialty. ${ }^{3}$ In their 2018 report, the Canadian Medical Association (CMA) acknowledged that gender inequity among medical leaders is an important problem. ${ }^{4}$ Only 8 of the 152 past presidents of the CMA were women. A woman first became dean of a Canadian medical school in 1999, 170 years after the first medical school was established, ${ }^{5}$ and only 8 women have been deans since then. Yu and colleagues analyzed data from the Association of American Medical Colleges on the faculty of United States medical schools from 1997 to 2008, and showed that when gender intersects with race and ethnicity, the gender leadership gap is even wider. For example, among internal medicine chairs, 12 were Asian men, 10 were Black (9 men, 1 woman), 7 were Hispanic (5 men, 2 women), and 137 were White (116 men, 21 women). It is also worth noting that, among faculty, only $11 \%$,

\section{KEY POINTS}

- Gender inequity persists in medicine and medical academia in Canada, particularly in leadership.

- Greater gender equity has been shown to be better for health policy-making and patient care.

- Evidence-informed, multipronged approaches that promote gender equity in medicine are required at all levels of medical organizations and for all stages of medical career progression.

9\%, $11 \%$ and $24 \%$ of Asian, Black, Hispanic and White women, respectively, were full professors compared with $21 \%, 18 \%, 19 \%$ and $36 \%$ of Asian, Black, Hispanic and White men, respectively. ${ }^{6}$

Several studies have documented the extent of gender inequity in academic medicine, where success is judged by productivity in grants, presentations, publications and mentored trainees. Gender gaps are apparent in national health research funding competitions at both the scientist level ${ }^{7}$ and project level. ${ }^{8}$ If more men in science are getting funding than women after controlling for factors such as age and experience, this further exacerbates disparity and negatively affects a woman's career trajectory. For example, the more grants a person holds, the more trainees they attract and the more successful and productive they are, ultimately leading to career promotion and tenure advancement. Clinical practice guidelines are used extensively to inform practice and are often widely cited, yet female clinicians are underrepresented on guideline panels and are less likely to be senior authors than men. ${ }^{9}$ Grand rounds are opportunities to model leaders and diversity in medicine; however, a 2018 retrospective study of presenters at medical grand rounds at 5 major academic hospitals in Canada showed that women are underrepresented. ${ }^{10}$ Women are more likely to work in lower paid and typically undervalued areas of medicine, ${ }^{11,12}$ obtain reference letters for medical school faculty positions that are less supportive than their male counterparts, ${ }^{13}$ and experience a decreased likelihood of being addressed by their professional title, ${ }^{14,15}$ than men. In both academia and in practice, women are paid less than their male counterparts even after adjusting for several factors, such as age, experience and 


\section{Box 1: The multidimensionality of gender}

- According to the World Health Organization, gender is a multifaceted concept that captures "the roles, behaviours, activities, attributes and opportunities that any society considers appropriate for girls and boys, and women and men." Gender is not binary; it is a multidimensional phenomenon. Gender inequity is largely underpinned by socially constructed gender norms, roles and relations. However, most of the medical literature describes gender as being binary (women and men) and as such, most of the research focuses on differences between women and men rather than considering intersectionality.

- Gender roles are shaped early in childhood and influence all aspects of human development and perceptions of the world, (e.g., traditional expectations for women to be caring homemakers and men to work outside the home). Traditional gender roles explain why women do more unpaid care than men at home and at work, which affects their work productivity.

- Gender norms are common, shared ideas of how people should speak, dress, groom and behave in social, workplace and private settings (e.g., assertiveness being seen as a masculine leadership trait and women being expected to behave submissively, which may lead to discrimination or differential opportunities based on gender).

- Gender relations refer to dynamics in relationships between genders that are determined by several factors (e.g., religion, culture or society), which can lead to inequities in power and access or control of resources. These inequities can result in, for instance, men having fewer consequences for uncivil behaviour or for engaging in workplace harassment than other genders.

workload; ${ }^{11,12}$ indeed, estimates suggest that women are paid an average of $30 \%$ to $40 \%$ less than men through fee-for-service models of payment for family doctors and specialists, respectively.

\section{What contributes to this gender inequity?}

The problem of gender inequity in medical leadership is not the result of too few candidates who are not men with the appropriate experience and training to fulfill leadership roles, nor can it be explained by merely suggesting that different genders do not have the same aspirations as men. ${ }^{16}$ Gender inequity is largely underpinned by socially constructed gender norms, roles and relations, as defined in Box 1. For example, gender roles explain why female clinicians with children spend 100.2 minutes more per day on household activities and child care than their male counterparts. ${ }^{17}$ This makes it more challenging for female clinicians with children to get ahead. Gender norms explain why more men are given leadership opportunities and have stronger letters of reference than other genders. Furthermore, gender relations explain why men have fewer consequences for uncivil behaviour or for harassment in the workplace compared with other genders. A recent observational study of operating room culture evaluated the prevalence and predictors of exposure to disruptive

\section{Box 2: Evidence used in this article}

We searched PubMed and MEDLINE for English-language articles published any time as of August 2020, using the words "solutions," "gender inequity" and "medicine." We selected randomized control trials, systematic reviews, meta-analyses and observational studies. We also searched for grey literature using Google and Google Scholar, bibliographies and reference lists of included articles, the Gender in Global Research group project folder established by Elsevier and various Canadian and international websites, including the Association of American Medical Colleges, the Association of Faculties of Medicine of Canada, the Society for Canadian Women in Science and Technology, the American Medical Women's Association and the Canadian Institutes of Health Research, Institute of Gender and Health.

behaviour in the operating room. ${ }^{18}$ Disruptive behaviour was described as a range of unacceptable workplace behaviours, including incivility, bullying and harassment. A further definition provided is "interpersonal behaviour (i.e., directed toward others or occurring in the presence of others) that results in a perceived threat to victims and/or witnesses and violates a reasonable person's standard of respectful behaviour." 18 The study found that clinicians who are women report more exposure to disruptive behaviour and are substantially less confident or empowered to take action to address incivility in their hospital and university settings. ${ }^{18}$ Gender and sexual harassment may be associated with environments that exhibit gender inequity in pay, opportunity and promotion. ${ }^{19,20}$ Disruptive behaviour and overt harassment likely endure within our medical institutions because the offenders are often considered invaluable to the organization for their stature, leadership, productivity or reputation, ${ }^{19,20}$ and are largely not held unaccountable for their actions, which further amplifies gender inequities.

\section{Why do we need gender equity in medicine?}

Ensuring gender equity in medicine is an issue of justice and rights. Having more physicians who are women and more women in health policy leadership also appears to enhance the provision of high-quality patient care. Large, wellconducted observational studies have shown that patients of female clinicians experience better quality of care for diabetes, ${ }^{21}$ and significantly lower rates of mortality, ${ }^{22-24}$ hospital readmissions ${ }^{22}$ and emergency department visits ${ }^{25}$ than those treated by male clinicians. ${ }^{22}$ One study considered that reasons for this may include that women spend more time with their patients, are more patient-centred in their approach and provide more evidence-based care. ${ }^{22}$ Two recent opinion pieces discuss research showing that female representation on corporate boards, such as hospital boards, results in more socially thoughtful decisions and less corruption. ${ }^{26,27}$ Without gender equity, we risk extinguishing creative solutions to complex health problems ${ }^{26}$ and, most importantly, limiting patient access to the best care. ${ }^{20}$ 


\section{How can we achieve gender equity in the medical profession?}

Although providing people with training in diversity and unconscious bias, as well as clarifying unprofessional behaviour, may seem like attractive solutions to gender inequity, ${ }^{28}$ such interventions represent a small step toward raising awareness of problems. Moreover, the impact of these interventions is short-lived, and they can be harmful when the blame for inequity is focused inappropriately and no systemic measures are put in place.

There is no quick fix for gender inequity. Multipronged interventions composed of a combination of structural and individual interventions (as summarized in Box 3 ) are needed to foster lasting and meaningful change. ${ }^{29-38}$ According to Hui and colleagues, ${ }^{39}$ implicit gender bias is pervasive across the continuum of medical training and practice. Therefore, solutions must begin with recognition of the systemic nature of the problem. Solutions should also be holistic and supported by professional organizations, including at the national (e.g., the CMA, the Association of Faculties of Medicine of Canada, the Royal College of Physicians and Surgeons of Canada and the College of Family Physicians of Canada), provincial (e.g., provincial and territorial medical associations) and local (e.g., hospital, clinic, practice and university leadership level) levels.

\section{Quantifying gender inequities}

Obtaining and publicly reporting gender and other intersectional data can increase awareness of inequities, as shown by a 2015 case study of gender equity among medical conference speakers, ${ }^{40}$ which showed that measurement highlighted the problem and, when combined with public accountability, provided incentive for change and to monitor impact. The work of both measuring and reporting and driving change to support gender equity must be recognized and adequately compensated.

\section{Championing behavioural and systemic change}

Drivers of behavioural and systemic change need to be championed from the top down. ${ }^{41}$ This was evident in a case study of an intervention that evaluated the effect of a top-down structural change within science, technology, engineering, mathematics and medicine faculties at Oregon State University. The intervention was an in-depth seminar designed to foster reflection on systems of oppression and power within university leadership. Findings led to the implementation of action plans and policies that shifted the faculties toward greater equity and justice on objective measures. Furthermore, when senior faculty exhibit behaviours in support of equity, it can lead to a more inclusive and supportive climate in academia. Thus, leaders of professional societies, as well as academic and health care organizations, should model the principles of equity. However, although role models in leadership are necessary, they are not sufficient to achieve equity. The core principles of equity, diversity, inclusion, mutual respect, collegiality and professionalism must be enshrined in all policies, programs and procedures, from undergraduate to postgraduate education, through to clinical practice and professional leadership. Organizations, through their boards
Box 3: Solutions to gender inequity in academic medicine*

Quantification of gender inequities in funding, publications, promotion and compensation

- Communicating gender statistics

- Annual reporting on the impact of gender equity efforts (completed and made publicly available to ensure accountability)

\section{Behavioural or systemic change}

- Recognition of the systemic nature of gender inequity and the need for systemic solutions from organizations

- Role modelling equity principles by the leaders of professional institutions (academic and health care)

- Enshrining core principles of equity, diversity, inclusion, mutual respect, collegiality and professionalism in all organizational policies

- Communication of clear objectives to address inequities, describing how it will be achieved with well-defined plans

- Open and transparent procedures and policies to protect whistleblowers

- Appropriate and evidence-based remediation for the perpetrator if an underlying cause (e.g., burnout or mental health issues) is identified

- Gender-inclusive language in recruitment, hiring, and grants and funding assessments

- Use of reverse quotas

- Search committees reflecting the diversity of the profession or the broader population, and committee awareness of gender bias in reference letters

- Gender bias training and champions of gender equity

- Seminar training, with a curriculum based on Systems of Oppression theories, using a formally trained search advocate

- Proportional approach for research grants

\section{Career flexibility}

- Integrated career-life planning, coaching to create a customized plan to meet both career and life goals, and a time-banking system

- Flexible policies, including family-friendly, parental and career flexibility policies

- Nongendered parental leave schemes

- Shortened workdays

- Policies prohibiting assigning work or sending emails in the evenings and on the weekend

Increased visibility, recognition and representation

- Career development planning

- Leadership program

- Ensure availability of role models to foster identity compatibility and belonging

- Social media campaign

Creating opportunities for development, mentorship and sponsorship

- Career advising plan

- Curriculum vitae review program

- Peer mentoring program

- Sponsorship program

Financial support

- Financial support for childbearing and caregiver responsibilities

- Lottery for research grants

*Solutions that combine several of these components are recommended. 
and administrative leadership, must communicate clear objectives to address inequities and describe how these objectives are going to be achieved. Organizations must also be held accountable. Furthermore, allies and whistleblowers of all genders who report unprofessional behaviour must be supported and protected by open and transparent procedures that enable them to speak up,,$^{18}$ and perpetrators of unprofessional behaviour must be remediated according to best practice and evidence relevant to the circumstances.

\section{Selection and hiring}

Advancing an organizational culture of equity in medicine should ideally begin with enrolment in medical school and continue through all stages of professional advancement. Because implicit gender bias is common and, by definition, largely unrecognized, ${ }^{42,43}$ gender bias training is necessary for people involved in candidate selection, although without clear measures to effect behaviour change such training may be insufficient. Open and transparent procedures and policies support more equitable hiring of academic and clinician candidates, ${ }^{11}$ and open search procedures (including job postings) should embed equity requirements. For example, all eligible candidates must be encouraged to apply and active strategies to increase the diversity of applicants should be undertaken. Job postings should use neutral language that does not implicitly favour one gender; online tools devoted to the use of gender inclusive language are available. ${ }^{44}$ Although specific processes to reduce implicit gender bias such as blinding can result in an increased proportion of applicants who are diverse, ${ }^{45}$ nongendered language has not been effective in reducing gender bias in the grant application process. ${ }^{46}$

In addition to receiving bias training, search committees should reflect the diversity of the population to raise the likelihood that diverse applicants will be treated equitably during the selection process. Having a search advocate who has received training sit on recruitment committees can also show commitment toward equity and inclusion, and can assist search committees in their efforts to avoid unconscious and unintentional biases. All committees should require training on equity, diversity and inclusivity to ensure the best candidate gets selected, independent of bias. ${ }^{41,43,47}$ Committee members should also be aware of gender bias in reference letters (e.g., a focus on relationships versus achievements for female candidates $\left.{ }^{48}\right)$. Nontraditional capability metrics, such as the impact of the candidate's work rather than number of publications, should be the focus of the interview, including new expertise in gender equity. Given that the outputs of female candidates may have been affected by time taken to have a family or unpaid labour at home, it is important to consider diverse measures when considering candidates' productivity and impact. Considering only number of publications, presentations and grants obtained will bias selection toward male candidates. Prioritizing other criteria such as ratings of the candidate by students, patients and peers, can allow for more equitable ranking. The use of reverse quotas ${ }^{49}$ (e.g., only $50 \%$ of the leadership can be men) should be encouraged to promote meritocracy and help neutralize male privilege. ${ }^{50}$

\section{Supporting women's careers}

Existing support for women to advance their careers is minimal and inadequate. Attracting and retaining talented candidates in academic medicine will require that institutions have policies to ensure career flexibility through a supportive environment that challenges "the ideal worker norm." ${ }^{1,52}$ Initiatives that promote team success with benefits that mitigate work-life and workwork conflicts can include integrated career-life planning, coaching to create a customized plan to meet both career and life goals and time-banking systems. ${ }^{53}$ Time-banking interventions measure unacknowledged work such as teaching, service and clinical activities, and acknowledges them with practical rewards in the form of support services that are meant to benefit career and personal goals by alleviating time pressure and by promoting career success. ${ }^{54}$ Parental leave and family-friendly policies include income-replacement plans that provide more resources to the family. ${ }^{55-57}$ Not specific to physicians, evidence suggests that up to 6 months of paid parental leave can increase the participation of women in the labour force and reduce wage inequalities. ${ }^{58}$ In addition, making parental leave available to both men and women is critical to ensuring equal economic opportunities. Two studies that analyzed California's paid family leave found that it increased the usual work hours of employed mothers of children aged $1-3$ years by $10 \%-17 \%$. The studies also showed an association of the policy with higher probabilities of work and employment for mothers 9-12 months after childbirth..$^{59,60}$ In addition, maternal earnings from 1 to 5 years after childbirth increase when paid maternity leave of moderate length is available. ${ }^{61,62}$ Financial support earmarked for faculty with caregiver responsibilities can result in staff retention and a greater likelihood of promotion. ${ }^{63}$

Minority groups lack role models and mentors who are women in academic medicine. To increase the visibility of diverse women in all areas of academic medicine, career advising plans can enhance confidence around professional selfadvocacy, achieving a promotion to the next academic rank and expanding training or job opportunities. ${ }^{64}$ Peer mentoring can contribute to increasing recognition and representation. ${ }^{65-69}$ Mentors and role models who are women in academic medicine have an important influence on career guidance, career choice, research productivity and personal development. ${ }^{70,71}$ Because of the shortage of women leaders in academic medicine, there might not always be women available to be mentors. Mentorship alone might also not be enough to support career advancement. Sponsorship, which is the intentional effort by a current leader to advocate for a woman to help her advance her career may be more effective. ${ }^{72}$ Sponsorship directly targets career advancement and is anchored in the sponsor's established network and substantial influence on decision-making processes or structures to provide critical professional opportunities for junior faculty. In the present context of a dearth of women leaders who wield that power in academic medicine, men must be evaluated based on how effectively they provide sponsorships for women. ${ }^{73}$

Organizational approaches, with proposed action plans and publicly reported, measurable effects in promoting good practice in the wider community, are required (Box 4). ${ }^{77,78}$ 
Box 4: The Athena Scientific Women's Academic Network Charter: an example of a multipronged solution to gender inequity in academia

The Athena Scientific Women's Academic Network (SWAN) charter encourages and commits universities in the United Kingdom to advance the careers of women in science, technology, engineering, mathematics and medicine. ${ }^{74} \mathrm{As}$ an award-based program, Athena SWAN promotes the progression of women to senior roles by removing obstacles to advancement, ensuring equal pay and mainstreaming support, through action at all levels of the institution. Peer-review panels assess applications, make suggestions on awards and provide applicants with constructive feedback. Categories of interventions include the following: selfassessment and monitoring; key career transition points; permanent and long-term contracts, including job security for academic-related and research staff; career development; promotion of flexible working, including management of career breaks; improvements in organization and culture with respect to gender equity; and a combination of complex, context-specific action planning and system-level organization.

Athena SWAN is widely used throughout the UK as a tool to address gender challenges in institutions for higher education. Women in the highest award category are more likely to be satisfied with performance and development reviews, to be familiar with criteria and processes for promotion, to have been encouraged to apply for promotion, to believe that there are flexible working practices, to be more optimistic about career prospects and to have a mentoring scheme available to them. ${ }^{74}$ Some evidence linked the charter to higher levels of engagement by women. ${ }^{74}$ White, middle-class women are the main beneficiaries of Athena SWAN. Athena SWAN and similar initiatives need to incorporate intersectionality and the effects of the overlap of race and other social identities (including gender) for women in science, technology, engineering, mathematics and medicine. Other countries have implemented similar programs, contextualized to their own setting, such as Science in Australia Gender Equity (SAGE) in Australia ${ }^{75}$ and the Dimensions Charter in Canada. ${ }^{76}$

\section{Conclusion}

Gender equity in medicine will occur when the culture shifts across the entire system. ${ }^{79}$ If gender equity is truly valued, robust research into the drivers of, and potential solutions to, gender inequity will be necessary for effective change. Some of the authors are currently working with colleagues from 7 countries to evaluate the efficacy of different types of gender equity interventions, supported by funding from the Canadian Institutes of Health Research. ${ }^{80}$ However, many evidence-based solutions can be adopted now, and there is no excuse for not working to change the climate and environment of the medical profession so that it is welcoming of diversity. The medical profession should be professional, be collegial, show mutual respect, and facilitate the full potential and contribution of all genders, races, ethnicities, religions and nationalities for the benefit of patient care. Equity will only be realized when everyone - regardless of gender and other differences - experiences equity in pay, promotions and other opportunities. There is no better time than now to implement policies to advocate for and support equity in medicine.

\section{References}

1. Gender and health. Geneva: World Health Organization. Available: www.who. int/health-topics/gender\#tab=tab_1 (accessed 2020 Nov. 17).

2. Glauser W. Rise of women in medicine not matched by leadership roles. CMAJ 2018;190:E479-80.

3. Jena $A B$, Khullar $D$, Ho O, et al. Sex differences in academic rank in US medical schools in 2014. JAMA 2015;314:1149-58.

4. Canadian Medical Association; Federation of Medical Women of Canada. Addressing gender equity and diversity in Canada's medical profession: a review. Ottawa: Canadian Medical Association.

5. Robb N. Canada has its first female dean -170 years after first medical school opened. CMAJ 1999;160:1042.

6. Yu PT, Parsa PV, Hassanein O, et al. Minorities struggle to advance in academic medicine: a 12-y review of diversity at the highest levels of America's teaching institutions. J Surg Res 2013;182:212-8.

7. Witteman HO, Hendricks M, Straus S, et al. Gender bias in CIHR Foundation grant awarding. Lancet 2019;394:e41-2.

8. Witteman HO, Hendricks M, Straus S, et al. Are gender gaps due to evaluations of the applicant or the science? A natural experiment at a national funding agency. Lancet 2019;393:531-40.

9. Merman E, Pincus D, Bell C, et al. Differences in clinical practice guideline authorship by gender. Lancet 2018;392:1626-8.

10. Buell D, Hemmelgarn BR, Straus SE. Proportion of women presenters at medical grand rounds at major academic centres in Canada: a retrospective observational study. BMJ Open 2018;8:e019796.

11. Cohen M, Kiran T. Closing the gender pay gap in Canadian medicine. CMAJ 2020;192:E1011-7.

12. Boesveld S. What's driving the gender pay gap in medicine? CMAJ 2020;192:E19-20.

13. Trix F, Psenka C. Exploring the color of glass: letters of recommendation for female and male medical faculty. Discourse Soc 2003;14:191-220.

14. Kang SK, Kaplan S. Working toward gender diversity and inclusion in medicine: myths and solutions. Lancet 2019;393:579-86.

15. Glauser W. How female physicians are supporting each other in addressing professional inequities. CMAJ 2019;191:E485-6.

16. Pololi LH, Civian JT, Brennan RT, et al. Experiencing the culture of academic medicine: gender matters, a national study. J Gen Intern Med 2013;28:201-7.

17. Ly DP, Jena AB. Sex differences in time spent on household activities and care of children among US physicians, 2003-2016. Mayo Clin Proc 2018;93:1484-7.

18. Villafranca A, Hiebert B, Hamlin C, et al. Prevalence and predictors of exposure to disruptive behaviour in the operating room. Can J Anaesth 2019;66:781-94.

19. Pattani R, Ginsburg S, Mascarenhas Johnson A, et al. Organizational factors contributing to incivility at an academic medical center and systems-based solutions: a qualitative study. Acad Med 2018;93:1569-75.

20. Choo EK, Byington CL, Johnson N-L, et al. From \#MeToo to \#TimesUp in health care: can a culture of accountability end inequity and harassment? Lancet 2019;393:499-502.

21. Berthold HK, Gouni-Berthold I, Bestehorn KP, et al. Physician gender is associated with the quality of type 2 diabetes care. J Intern Med 2008;264:340-50.

22. Tsugawa Y, Jena AB, Figueroa JF, et al. Comparison of hospital mortality and readmission rates for medicare patients treated by male vs female physicians. JAMA Intern Med 2017;177:206-13.

23. Wallis CJ, Ravi B, Coburn N, et al. Comparison of postoperative outcomes among patients treated by male and female surgeons: a population based matched cohort study. BMJ 2017;359:j4366.

24. Greenwood BN, Carnahan S, Huang L. Patient-physician gender concordance and increased mortality among female heart attack patients. Proc Natl Acad Sci U S A 2018;115:8569-74.

25. Dahrouge S, Seale E, Hogg W, et al. A comprehensive assessment of family physician gender and quality of care: a cross-sectional analysis in Ontario, Canada. Med Care 2016;54:277-86.

26. Fine C, Sojo V. Women's value: beyond the business case for diversity and inclusion. Lancet 2019;393:515-6. 
27. Downs JA, Reif LK, Hokororo A, et al. Increasing women in leadership in global health. Acad Med 2014;89:1103-7.

28. Tricco AC, Rios P, Zarin W, et al. Prevention and management of unprofessional behaviour among adults in the workplace: a scoping review. PLoS One 2018; 13:e0201187.

29. Richman RC, Morahan PS, Cohen DW, et al. Advancing women and closing the leadership gap: the Executive Leadership in Academic Medicine (ELAM) program experience. J Womens Health Gend Based Med 2001;10:271-7.

30. McDade SA, Richman RC, Jackson GB, et al. Effects of participation in the Executive Leadership in Academic Medicine (ELAM) program on women faculty's perceived leadership capabilities. Acad Med 2004;79:302-9.

31. Dannels SA, Yamagata H, McDade SA, et al. Evaluating a leadership program: a comparative, longitudinal study to assess the impact of the Executive Leadership in Academic Medicine (ELAM) program for women. Acad Med 2008; 83:488-95.

32. Bauman MD, Howell LP, Villablanca AC. The women in medicine and health science program: an innovative initiative to support female faculty at the University of California Davis School of Medicine. Acad Med 2014;89:1462-6.

33. Levine RB, González-Fernández M, Bodurtha J, et al. Implementation and evaluation of the Johns Hopkins University School of Medicine leadership program for women faculty. J Womens Health (Larchmt) 2015;24:360-6.

34. Ovseiko PV, Chapple A, Edmunds LD, et al. Advancing gender equality through the Athena SWAN Charter for Women in Science: an exploratory study of women's and men's perceptions. Health Res Policy Syst 2017;15:12.

35. Kalpazidou Schmidt E, Ovseiko PV, Henderson LR, et al. Understanding the Athena SWAN award scheme for gender equality as a complex social intervention in a complex system: analysis of Silver award action plans in a comparative European perspective. Health Res Policy Syst 2020;18:19.

36. Rosser SV, Barnard S, Carnes M, et al. Athena SWAN and ADVANCE: effectiveness and lessons learned. Lancet 2019;393:604-8.

37. Dannels SA, McLaughlin JM, Gleason KA, et al. Dental school deans' perceptions of the organizational culture and impact of the ELAM program on the culture and advancement of women faculty. J Dent Educ 2009;73:676-88.

38. McDade SA, Nooks KA, King PJ, et al. A window into the culture of leadership within higher education through the leadership definitions of women faculty: a case study of ELAM women faculty alumnae. NASPA Journal About Women in Higher Education 2008;1:76-104.

39. Hui K, Sukhera J, Vigod S, et al. Recognizing and addressing implicit gender bias in medicine. CMAJ 2020;192;E1269-70.

40. Casadevall A. Achieving speaker gender equity at the American Society for Microbiology general meeting. MBio 2015;6:e01146.

41. Shaw SM, Bothwell M, Furman K, et al. Advancing women in STEM: institutional transformation. Lancet 2019;393:e17-8.

42. Girod S, Fassiotto M, Grewal D, et al. Reducing implicit gender leadership bias in academic medicine with an educational intervention. Acad Med 2016;91: 1143-50.

43. Carnes M, Bartels CM, Kaatz A, et al. Why is John more likely to become department chair than Jennifer? Trans Am Clin Climatol Assoc 2015;126:197-214.

44. Gender decoder for job ads. Available: http://gender-decoder.katmatfield. com/ (accessed 2020 Nov. 19).

45. Alvarez SNE, Jagsi R, Abbuhl SB, et al. Promoting gender equity in grant making: What can a funder do? Lancet 2019;393:e9-11.

46. Tricco AC, Thomas SM, Antony J, et al. Strategies to prevent or reduce gender bias in peer review of research grants: a rapid scoping review. PLOS One 2017;12:e0169718.

47. Carr PL, Gunn C, Raj A, et al. Recruitment, promotion, and retention of women in academic medicine: how institutions are addressing gender disparities. Womens Health Issues 2017;27:374-81.

48. Grimm LJ, Redmond RA, Campbell JC, et al. Gender and racial bias in radiology residency letters of recommendation. J Am Coll Radiol 2020;17:64-71.

49. Coe IR, Wiley R, Bekker L-G. Organisational best practices towards gender equality in science and medicine. Lancet 2019;393:587-93.

50. Murray R. Quotas for men: reframing gender quotas as a means of improving representation for all. Am Polit Sci Rev 2014;108:520-32.
51. Valantine $\mathrm{H}$, Sandborg $\mathrm{Cl}$. Changing the culture of academic medicine to eliminate the gender leadership gap: 50/50 by 2020. Acad Med 2013;88:1411-3.

52. Howell LP, Beckett LA, Villablanca AC. Ideal worker and academic professional identity: perspectives from a career flexibility educational intervention. Am J Med 2017;130:1117-25.

53. Fassiotto M, Simard C, Sandborg C, et al. An integrated career coaching and time-banking system promoting flexibility, wellness, and success: a pilot program at Stanford University School of Medicine. Acad Med 2018;93:881-7.

54. Fassiotto M, Maldonado YA. A time banking system to support workplace flexibility. Stanford Medicine, WellMD. Available: https://wellmd.stanford.edu/content/ dam/sm/wellmd/documents/Time-banking-system.pdf (accessed 2020 Nov. 19).

55. Villablanca AC, Beckett L, Nettiksimmons J, et al. Career flexibility and familyfriendly policies: an $\mathrm{NIH}$-funded study to enhance women's careers in biomedical sciences. J Womens Health (Larchmt) 2011;20:1485-96.

56. Villablanca AC, Li Y, Beckett LA, et al. Evaluating a medical school's climate for women's success: outcomes for faculty recruitment, retention, and promotion. J Womens Health (Larchmt) 2017;26:530-9.

57. Patnaik A. Reserving time for Daddy: the consequences of fathers' quotas. $J$ Labor Econ 2019;37:1009-59.

58. Brugiavini A, Pasini G, Trevisan E. The direct impact of maternity benefits on leave taking: evidence from complete fertility histories. Adv Life Course Res 2013;18:46-67.

59. Baum CL II, Ruhm CJ. The effects of paid family leave in California on labor market outcomes. J Policy Anal Manage 2016;35:333-56.

60. Rossin-Slater M, Ruhm CJ, Waldfogel J. The effects of California's paid family leave program on mothers' leave-taking and subsequent labor market outcomes. J Policy Anal Manage 2013;32:224-45.

61. Waldfogel J. The family gap for young women in the United States and Britain: Can maternity leave make a difference? J Labor Econ 1998;16:505-45.

62. Rasmussen AW. Increasing the length of parents' birth-related leave: the effect on children's long-term educational outcomes. Labour Econ 2010;17:91-100.

63. Jagsi R, Butterton JR, Starr R, et al. A targeted intervention for the career development of women in academic medicine. Arch Intern Med 2007;167:343-5.

64. Gottlieb AS, Travis EL. Rationale and models for career advancement sponsorship in academic medicine: the time is here; the time is now. Acad Med 2018;93:1620-3.

65. Von Feldt JM, Bristol M, Sonnad S, et al. The brief CV review session: one component of a mosaic of mentorship for women in academic medicine. J Natl Med Assoc 2009;101:873-80.

66. Gardiner M, Tiggemann M, Kearns $\mathrm{H}$, et al. Show me the money! An empirical analysis of mentoring outcomes for women in academia. High Educ Res Dev 2007;26:425-42.

67. Files JA, Blair JE, Mayer AP, et al. Facilitated peer mentorship: a pilot program for academic advancement of female medical faculty. J Womens Health (Larchmt) 2008;17:1009-15.

68. Varkey P, Jatoi A, Williams A, et al. The positive impact of a facilitated peer mentoring program on academic skills of women faculty. BMC Med Educ 2012;12:14.

69. Dutta R, Hawkes SL, Kuipers E, et al. One year outcomes of a mentoring scheme for female academics: a pilot study at the Institute of Psychiatry, King's College London. BMC Med Educ 2011;11:13.

70. Rosenthal L, Levy SR, London B, et al. In pursuit of the MD: the impact of role models, identity compatibility, and belonging among undergraduate women. Sex Roles 2013;68:464-73.

71. Butkus R, Serchen J, Moyer DV, et al. Achieving gender equity in physician compensation and career advancement: a position paper of the American College of Physicians. Ann Intern Med 2018;168:721-3.

72. Spector ND, Asante PA, Marcelin JR, et al. Women in pediatrics: progress, barriers, and opportunities for equity, diversity, and inclusion. Pediatrics 2019;144:e20192149.

73. Bates C, Gordon L, Travis E, et al. Striving for gender equity in academic medicine careers: a call to action. Acad Med 2016;91:1050-2.

74. Graves A, Rowell A, Hunsicker E. An impact evaluation of the Athena SWAN Charter. Newcastle upon Tyne (UK): Ortus Economic Research; Loughborough (UK): Loughborough University; 2019. 
75. SAGE: Science in Australia Gender Equity [main page]. Available: www. sciencegenderequity.org.au (accessed 2020 Nov. 17).

76. Equity, diversity and inclusion. Ottawa: Natural Sciences and Engineering Research Council. Available: www.nserc-crsng.gc.ca/NSERC-CRSNG/EDI-EDI/ Dimensions-Charter_Dimensions-Charte_eng.asp (accessed 2020 Nov. 30).

77. Jagsi R, Spector ND. Leading by design: lessons for the future from 25 years of the Executive Leadership in Academic Medicine (ELAM) program for women. Acad Med 2020;95:1479-82.
78. Plank-Bazinet JL, Heggeness ML, Lund PK, et al. Women's careers in biomedical sciences: implications for the economy, scientific discovery, and women's health. J Womens Health (Larchmt) 2017;26:525-9.

79. Pritlove C, Juando-Prats C, Ala-Leppilampi K, et al. The good, the bad, and the ugly of implicit bias. Lancet 2019;393:502-4.

80. Tricco AC, Lachance CC, Rios P, et al. Global evidence of gender inequity in academic health research: a living scoping review protocol. JBI Evid Synth 2020;18:2181-93.

\section{Competing interests: None declared.}

This article was solicited and has been peer reviewed.

Affiliations: Knowledge Translation Program (Tricco, Peer, Straus), Li Ka Shing Knowledge Institute, St. Michael's Hospital, Unity Health Toronto; Epidemiology Division and Institute for Health Policy, Management, and Evaluation (Tricco), Dalla Lana School of Public Health, University of Toronto, Toronto, Ont.; School of Sociology and Anthropology (Bourgeault), University of Ottawa, Ottawa, Ont.; Department of Family Medicine (Moore), McMaster University, Hamilton, Ont.; Department of Family and Community Medicine (Grunfeld), and Department of Geriatric Medicine (Straus), University of Toronto, Toronto, Ont.
Contributors: Andrea Tricco wrote the first draft of the manuscript. All of the authors revised it critically for important intellectual content, gave final approval of the version to be published and agreed to be accountable for all aspects of the work.

Funding: Andrea Tricco is funded by a Tier 2 Canada Research Chair in Knowledge Synthesis. Ivy Bourgeault is funded from the University of Ottawa through the Research Chair in Gender, Diversity and the Professions and from Status of Women Canada, ON 16255, Empowering Women Leaders in Health. Eva Grunfeld is funded by a physician scientist award from the Ontario Institute for Cancer research and by the Giblon Chair in family medicine research. Sharon Straus is funded by a Tier 1 Canada Research Chair in Knowledge Translation.
Content licence: This is an Open Access article distributed in accordance with the terms of the Creative Commons Attribution (CC BY-NC-ND 4.0) licence, which permits use, distribution and reproduction in any medium, provided that the original publication is properly cited, the use is noncommercial (i.e., research or educational use), and no modifications or adaptations are made. See: https://creativecommons. org/licenses/by-nc-nd/4.0/

Acknowledgement: The authors would like to thank Shazia Siddiqui for helping format the paper.

Correspondence to: Andrea Tricco, Andrea.Tricco@unityhealth.to 